\title{
Reporting Quality of Diagnostic Accuracy Studies in Laboratory Medicine: Adherence to Standards for Reporting of Diagnostic Accuracy Studies (STARD) 2015
}

Mi-Ae Jang (®), M.D., Ph.D. ${ }^{1, *}$, Bohyun Kim $\bullet$, M.D., Ph.D. ${ }^{2, *}$, and You Kyoung Lee $\mathbb{1}$, M.D., Ph.D. ${ }^{1}$

${ }^{1}$ Department of Laboratory Medicine and Genetics, Soonchunhyang University Bucheon Hospital, Soonchunhyang University College of Medicine, Bucheon, Korea; ${ }^{2}$ Department of Laboratory Medicine, Soonchunhyang University Cheonan Hospital, Soonchunhyang University College of Medicine, Cheonan, Korea

Background: Poor reporting quality in diagnostic accuracy studies hampers an adequate judgment of the validity of the study. The Standards for Reporting of Diagnostic Accuracy Studies (STARD) statement was published to improve the reporting quality of diagnostic accuracy studies. This study aimed to evaluate the adherence of diagnostic accuracy studies published in Annals of Laboratory Medicine (ALM) to STARD 2015 and to identify directions for improvement in the reporting quality of these studies.

Methods: Two independent authors assessed articles published in ALM between 20122018 for compliance with 30 STARD 2015 checklist items to identify all eligible diagnostic accuracy studies published during this period. We included 66 diagnostic accuracy studies. A total of the fulfilled STARD items were calculated, and adherence was analyzed on an individual-item basis.

Results: The overall mean \pm SD number of STARD items reported for the included studies was $11.2 \pm 2.7$. Only five $(7.6 \%)$ studies adhered to more than $50 \%$ of the 30 items. No study satisfied more than $80 \%$ of the items. Large variability in adherence to reporting standards was detected across items, ranging from 0\% to $100 \%$.

Conclusions: Adherence to STARD 2015 is suboptimal among diagnostic accuracy studies published in ALM. Our study emphasizes the necessity of adherence to STARD to improve the reporting quality of future diagnostic accuracy studies to be published in ALM.

Key Words: Adherence, Annals of Laboratory Medicine, Diagnostic test, Laboratory, Standards for reporting of diagnostic accuracy

\author{
Received: May 19, 2019 \\ Revision received: August 23, 2019 \\ Accepted: November 22, 2019

\section{Corresponding author:} \\ You Kyoung Lee, M.D., Ph.D. \\ Department of Laboratory Medicine and \\ Genetics, Soonchunhyang University \\ Bucheon Hospital, Soonchunhyang University \\ College of Medicine, 170 Jomaru-ro, \\ Wonmi-gu, Bucheon 14587, Korea \\ Tel: +82-32-621-5941 \\ Fax: +82-032-621-5944. \\ E-mail: cecilia@schmc.ac.kr
}

*These authors contributed equally to this study.

\section{(i) \$}

() Korean Society for Laboratory Medicine This is an Open Access article distributed under the terms of the Creative Commons Attribution Non-Commercial License (http://creativecommons.org/licenses/by-nc/4.0) which permits unrestricted non-commercial use, distribution, and reproduction in any medium, provided the original work is properly cited.

\section{INTRODUCTION}

Diagnostic tests are indispensable in clinical practice as they inform clinicians about the likelihood that a patient has the suspected target disease or condition and guide subsequent decisions on further testing or treatment [1]. Accuracy is an important feature of any diagnostic testing, and diagnostic accuracy is evaluated by comparing results of the test of interest (index test) with those of a reference standard in a series of patients suspected of having a target condition. The results are typically expressed in measures, such as sensitivity and specificity, positive and negative predictive values, likelihood ratios, and area under the receiver operating characteristic (ROC) curve [2-4]. Diagnostic accuracy studies are at risk of several types of bias, which 
is a systematic difference in an observed measurement from the true value [5]. Major sources of bias in diagnostic accuracy studies include methodological deficiencies in participant selection and applicability, data collection, test execution and interpretation, and data analysis $[5,6]$. In addition, diagnostic accuracy studies are often not reported completely [7], which hinders a reader's ability to evaluate the risk of bias and to determine the generalizability of the study findings, and limits reproducibility.

In 2003, Standards for Reporting of Diagnostic Accuracy (STARD), composed of a list of 25 essential items that should be reported in every study report, were published to increase the transparency and completeness of reporting diagnostic accuracy studies [8, 9]. STARD are general guidelines designed to be applied to all types of diagnostic accuracy studies rather than focusing on specific issues or categories of medical tests [2-4]. This includes prognostic studies that could classify patients based on future events, monitoring studies that require testing to detect or predict an adverse event or lack of response, and studies that assess treatment selection markers [2-4]. The STARD initiative has been adopted by more than 200 journals, spanning basic research to medicine [5]. In 2015, the STARD guidelines were updated [2-4], and the essential items were increased to 30. The new standard covers the title (item 1), abstract (item 2), introduction (items 3 and 4), methods (items 5-18), results (items 19-25), and discussion (items 26 and 27), and requires additional information (items 28-30) about the study protocol and funding sources [2-4]. Since the publication of STARD, several evaluations have shown modest improvements in reporting diagnostic accuracy research [10-12].

Annals of Laboratory Medicine (ALM; ISSN 2234-3806) is the official journal of Korean Society for Laboratory Medicine and is indexed both in Medline and PubMed [13]. Since its name was changed from Korean Journal of Laboratory Medicine (ISSN 1598-6535) to ALM in 2012, it has consistently published numerous articles in various fields, including diagnostic hematology, clinical chemistry, clinical microbiology, diagnostic immunology, transfusion medicine, diagnostic genetics, laboratory informatics, and general laboratory medicine [13]. However, STARD have not been included in the instructions for authors by ALM.

The level of adherence of laboratory diagnostic accuracy studies to STARD 2015 is unknown in Korea. Assessing the basic status of adherence to STARD is critical and would enable us to determine and improve existing deficiencies. Thus, this study aimed to evaluate adherence of diagnostic accuracy studies published in ALM from inception in 2012 to 2018 to STARD 2015.

\section{MATERIALS AND METHODS}

\section{Study selection}

This was a cross-sectional study that evaluated all research papers published in ALM between 2012 and 2018 without distinguishing publication before or after STARD 2015 announcement. Studies for assessing the adherence to STARD 2015 were selected if they met the following inclusion criteria: (1) the diagnostic accuracy of one or more laboratory index tests was evaluated against a reference standard in human subjects and (2) at least one estimate of diagnostic accuracy, such as sensitivity, specificity, positive and negative predictive values, and ROC curve, was reported. We excluded studies, in which the index test or reference standard test was not clear, studies that compared index tests, studies that verified analytical performance, multivariable prediction model study, and letters. Two authors (M.A.J. and B.K.) independently screened the titles and abstracts of all the retrieved studies to evaluate their potential relevance. The full texts of all potentially relevant studies were assessed in duplicate. If an article was considered potentially eligible by at least one author, the full text was assessed independently by both authors against the inclusion criteria. Disagreements were discussed and resolved in consensus meetings.

Seven hundred thirty studies were published in ALM between 2012 and 2018, of which 352 were deemed potentially eligible after screening (Fig. 1). The excluded articles were letters ( $\mathrm{N}=$ 232), case reports or series $(N=111)$, review articles $(N=29)$, editorials $(N=5)$, or guidelines $(N=1)$. After reviewing the full texts, 66 (9.0\%, 66/730) diagnostic accuracy studies were included in the final analysis (Supplemental Data Table S1). The selection process is illustrated in Fig. 1.

\section{Adherence to STARD 2015}

The STARD 2015 list consists of 30 essential items grouped in six sections: title and abstract, introduction, methods, results, discussion, and other information [2-4]. Several STARD 2015 items have more than one sub-item. For example, item 2 (structured abstract) is divided into 10 sub-items (2a, identification as a diagnostic accuracy study; 2b, study objectives; 2c, data collection; $2 d$, eligibility criteria; $2 \mathrm{e}$, selection of participants; $2 \mathrm{f}$, description of the index test and reference standard; $2 \mathrm{~g}$, numbers of participants with and without the target condition; $2 \mathrm{~h}$, estimates of diagnostic accuracy and precision; $2 \mathrm{i}$, general interpretation of the results; and 2j, implications for practice) [14] that are scored independently. Items 10, 12, and 13 on the methods section comprise two sub-items applicable to the index test 


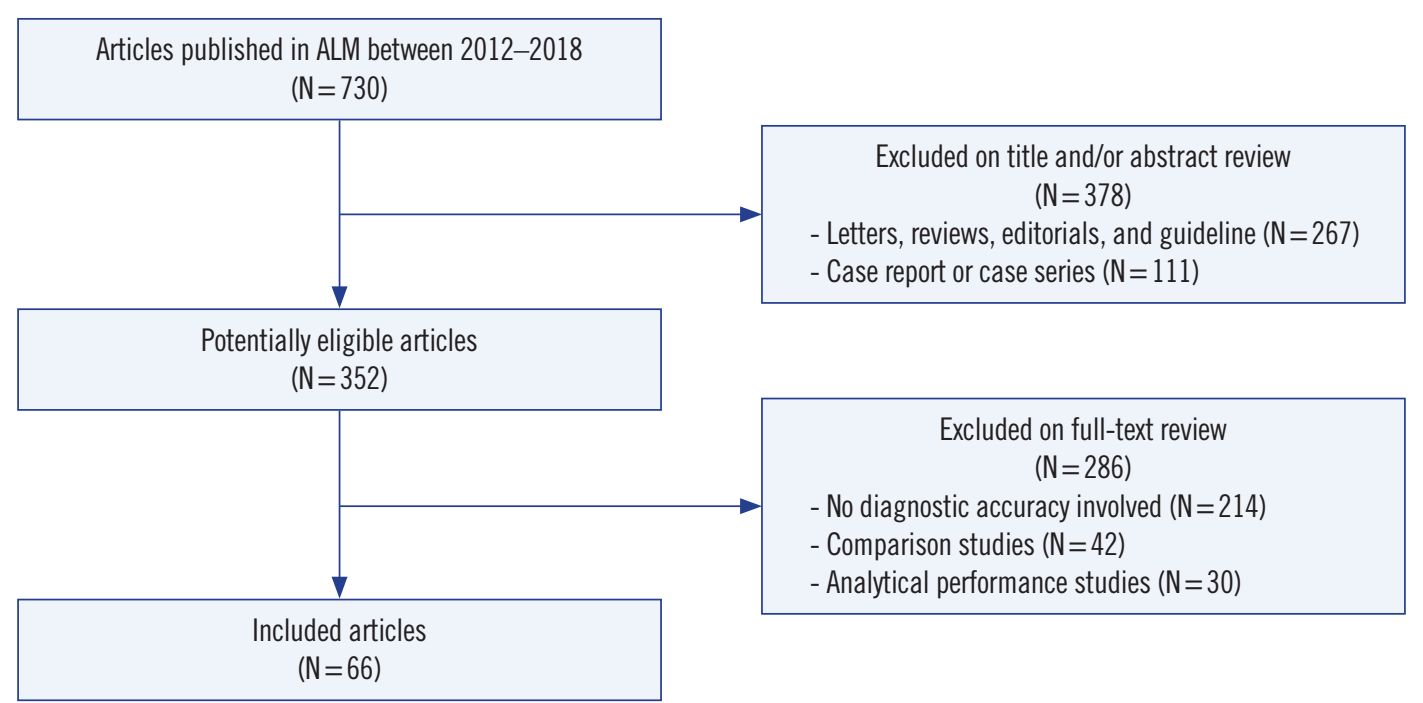

Fig. 1. Flow chart showing the selection procedure for diagnostic accuracy study reports published in Annals of Laboratory Medicine (ALM) between 2012 and 2018 in this study.

(10a, 12a, and 13a) and to the reference standard (10b, 12b, and $13 \mathrm{~b}$ ). Among them, sub-items $12 \mathrm{a}$ and $12 \mathrm{~b}$ on test result cut-off or category are further subdivided into more specific items for definition and rationale (12a, definition; 12a, rationale; 12b, definition; and $12 \mathrm{~b}$, rationale). In addition to the above items, we identified potentially relevant contents in an item that might be helpful when analyzed in detail. For example, item 3 (scientific and clinical background in the introduction) was divided into two sub-items (3a for intended use and 3b for clinical role of index test) for more detailed analysis.

Fulfillment of an item was recorded as 1 point. Items with multiple sub-items were scored with fractional points for each sub-item, adding up to a maximum total of 1 point. For example, the 10 sub-items of item 2 were recorded as 0.1 point each. Thus, the total maximum score was 30 points (i.e. it ranged from 0 - none of the items sufficiently reported, to 30 - all items sufficiently reported). Data analysis and the scoring method largely followed practices established in similar previous studies [10, 15, 16]. Detailed descriptions of compliance with STARD 2015 are given in Supplemental Data Table S2.

Each study was evaluated by two independent authors (M.A.J. and B.K.). To ensure high agreement among authors on each item, they first received an educational session on reviewing STARD 2015 and related literature. We referred to a document providing an explanation and elaboration of STARD 2015 for a detailed rationale behind the rating of each item [17]. Before STARD scoring, we conducted pilot scoring on three diagnostic accuracy studies, and refined the description of each item and prepared a final data extraction form based on several discussions. Discrepancies between the two authors were resolved through discussions in consensus meetings and during a final review by a third expert (Y.K.L).

\section{Statistical analysis}

The overall mean number of STARD items reported were determined. The two authors' (M.A.J. and B.K.) agreement on compliance with the assessment for STARD 2015 was evaluated based on Cohen's kappa coefficient as follows: <0.00, poor; 0.00-0.20, slight; 0.21-0.40, fair; 0.41-0.60, moderate; 0.610.80 , substantial; and $0.81-1.00$, almost perfect [18]. One-way analysis of variance was used to compare fulfilled STARD items of the diagnostic accuracy studies published in ALM by year. Statistical analysis was conducted using SPSS Statistics for Windows version 25.0 (IBM Corp., Armonk, NY, USA). A two-sided $P<0.05$ was considered statistically significant.

\section{RESULTS}

\section{Overall adherence to STARD 2015}

Characteristics of the articles included for final analysis are summarized in Table 1. The overall mean (SD) number of STARD item for the 66 diagnostic accuracy studies in ALM was 11.2 \pm 2.7 (Table 1). Inter-author agreement in compliance assessment for STARD 2015 was almost perfect, with a kappa value of 0.9. Only five $(7.6 \%)$ studies reported more than $50 \%$ of the 30 items (total fulfilled STARD items $>15$ ). No study satisfied more than $80 \%$ 
Table 1. Characteristics of diagnostic accuracy studies published in ALM between 2012 and 2018 and adherence to STARD 2015

\begin{tabular}{|c|c|c|}
\hline Characteristic & $\begin{array}{c}\text { Number (\%) of } \\
\text { studies }\end{array}$ & $\begin{array}{c}\text { Mean STARD items } \\
\text { reported }( \pm S D)\end{array}$ \\
\hline Total & $66(100.0)$ & $11.2 \pm 2.7$ \\
\hline \multicolumn{3}{|l|}{ Discipline category } \\
\hline Clinical microbiology & $37(56.1)$ & $10.1 \pm 2.3$ \\
\hline Diagnostic immunology & $11(16.7)$ & $12.2 \pm 2.2$ \\
\hline Clinical chemistry & $8(12.1)$ & $14.6 \pm 2.0$ \\
\hline Diagnostic hematology & $7(10.6)$ & $11.6 \pm 2.0$ \\
\hline General laboratory medicine & $2(3.0)$ & $13.0 \pm 2.1$ \\
\hline Diagnostic genetics & $1(1.5)$ & NA \\
\hline \multicolumn{3}{|l|}{ Publication type } \\
\hline Original article & $55(83.3)$ & $11.5 \pm 2.7$ \\
\hline Brief communication & $11(16.7)$ & $9.9 \pm 2.2$ \\
\hline \multicolumn{3}{|l|}{ Publication year } \\
\hline 2012 & $8(12.1)$ & $10.2 \pm 2.1$ \\
\hline 2013 & $10(15.2)$ & $11.3 \pm 2.3$ \\
\hline 2014 & $7(10.6)$ & $9.9 \pm 2.3$ \\
\hline 2015 & $12(18.2)$ & $10.2 \pm 2.4$ \\
\hline 2016 & $7(10.6)$ & $11.5 \pm 3.4$ \\
\hline 2017 & $10(15.2)$ & $11.6 \pm 2.4$ \\
\hline 2018 & 12 (18.2) & $13.1 \pm 2.9$ \\
\hline
\end{tabular}

Abbreviations: ALM, Annals of Laboratory Medicine; NA, not applicable; STARD, Standards for Reporting of Diagnostic Accuracy.

of the items (total fulfilled STARD items $>24$ ). The fulfilled number of STARD items were not significantly different from year to year.

\section{Item-specific adherence to STARD 2015}

Item-by-item adherence of the 66 diagnostic accuracy studies in ALM to the STARD 2015 is summarized in Table 2. Overall, adherence to STARD 2015 for each item varied widely, ranging from $0 \%$ to $100 \%$. Eleven items or sub-items were reported in more than $80 \%$ of the studies: title or abstract (item 1 ), abstract (items 2a, 2b, 2i, and 2j), introduction (items 3a and 4a), methods (items $8 b$ and $10 a$ ), results (item 24), and discussion (item 27a). Three of these items were reported in all studies (items $2 \mathrm{~b}, 3 \mathrm{a}$, and $4 \mathrm{a}$ ).

Conversely, 23 STARD items or sub-items were adhered to $<30 \%$ of the studies: abstract (items $2 \mathrm{c}, 2 \mathrm{e}$, and $2 \mathrm{~h}$ ), introduction (items $3 b$ and $4 b$ ), methods (items $6,7,12 b, 13 a, 13 b, 15$, 16,17 , and 18), results (items 19, 20,21a, 21b, 22, and 25), discussion (item 27b), and other information (items 28 and 29). None of the studies showed adherence to items 13a, 16, or 25.

\section{DISCUSSION}

We investigated the adherence of diagnostic accuracy studies published in ALM between 2012 and 2018 to STARD 2015. The reporting quality of diagnostic accuracy studies was suboptimal, with an overall STARD adherence of only 37.3\% (11.2/30 items) and high variability across items.

In comparison with previous assessments of adherence to STARD 2015, the average number of STARD items reported in the current study is low. In 2017, Michelessi, et al. [19] reported an adherence of $54.1 \%$ (16.8/31 items) in studies on glaucoma. In 2018, Hong, et al. [20] reported a higher adherence in their evaluation of imaging studies assessing accuracy (55.3\%, 16.6/30 items) [20]. A systematic review of 90 laboratory diagnostic accuracy studies on tuberculosis, malaria, and HIV revealed an overall STARD adherence of 54.4\% (13.6/25 items) [11, 21]. Another study of imaging and laboratory diagnostic accuracy studies revealed a high adherence rate of $61.2 \%$ (15.3/25 items) [10]. Choi, et al. [16] identified a substantially higher adherence among 63 imaging studies (74\%, 20/27 items). Therefore, we believe that differences in research fields do not explain differences in adherence to STARD. Rather, we hypothesize that the fact that ALM does not require authors to adhere to STARD accounts for the low adherence observed in the current study. Previous studies have shown that the numbers of reported STARD items are higher in STARD-adopting than those in non-adopting journals $[10,20]$.

Several STARD items have been infrequently reported and are in need of improvement. In the introduction of a scientific study, the authors should describe the intended use and clinical role of the index test under evaluation (items $3 a$ and $3 b$ ), and study objectives and testable hypotheses (items $4 a$ and $4 b$ ). The clinical role of the index test refers to its anticipated position relative to other existing tests, such as a triage, add-on, or replacement [17]. Hypotheses are defined as acceptance criteria for a single test, such as the minimum level of sensitivity or specificity, which guide the calculation of the sample size required for the study [8]. Only $14 \%$ and $12 \%$ of the diagnostic accuracy studies in ALM properly reported the clinical role of the test and hypothesis, respectively (Table 2). In addition, several items related to participants, such as items 7, 9, 19, 20,21, and 22, were poorly reported in more than two-thirds of the studies. This information is important because test performance is not fixed and may vary in different settings and among patients with different characteristics [5, 22].

Data analysis was also often poorly reported. For example, 
Jang MA, et al.

Adherence to STARD 2015

Table 2. Adherence to individual STARD 2015 items

\begin{tabular}{|c|c|c|}
\hline Report section & Item number and description & Number $(\%)$ of studies, $\mathrm{N}=66$ \\
\hline Title or abstract & 1. Identification as a diagnostic accuracy test & $60(91)$ \\
\hline \multirow[t]{10}{*}{ Abstract } & 2a. Identification as diagnostic accuracy test & $60(91)$ \\
\hline & 2b. Study objectives & $66(100)$ \\
\hline & 2c. Data collection & $9(14)$ \\
\hline & 2d. Eligibility criteria & $27(41)$ \\
\hline & 2e. Whether participants formed a consecutive, random, or convenience series & $5(8)$ \\
\hline & 2f. Description of the index test and reference standard & $50(76)$ \\
\hline & 2g. Numbers of participants with and without the target condition & $27(41)$ \\
\hline & 2h. Estimates of diagnostic accuracy and precision & $14(21)$ \\
\hline & 2i. General interpretation of the results & $65(98)$ \\
\hline & 2j. Implications for practice, including the intended uses of the index test & $62(94)$ \\
\hline \multirow[t]{4}{*}{ Introduction } & 3a. Intended use of the index test & $66(100)$ \\
\hline & 3b. Clinical role of the index test & $9(14)$ \\
\hline & 4a. Study objectives & $66(100)$ \\
\hline & 4b. Hypotheses & $8(12)$ \\
\hline \multirow[t]{20}{*}{ Methods } & 5. Data collection (prospective or retrospective) & $25(38)$ \\
\hline & 6. Eligibility criteria & $20(30)$ \\
\hline & 7. On what basis potentially eligible participants were identified & $13(20)$ \\
\hline & 8a. Study location & $52(79)$ \\
\hline & 8b. Study dates & $59(89)$ \\
\hline & 9. Participant sampling (consecutive, random, or convenience) & $21(32)$ \\
\hline & 10a. Details to allow replication of the index test & $53(80)$ \\
\hline & 10b. Details to allow replication of the reference standard & $41(62)$ \\
\hline & 11. Rationale for choosing the reference standard & $34(52)$ \\
\hline & 12a. Definition of test positivity cut-offs of the index test & $35(53)$ \\
\hline & 12a. Rationale for test positivity cut-offs of the index test & $24(36)$ \\
\hline & 12b. Definition of test positivity cut-offs of the reference standard & $32(48)$ \\
\hline & 12b. Rationale for test positivity cut-offs of the reference standard & $20(30)$ \\
\hline & 13a. Blind to the index test & $0(0)$ \\
\hline & 13b. Blind to the reference standard & $1(2)$ \\
\hline & 14. Methods for estimating diagnostic accuracy & $50(76)$ \\
\hline & 15. How indeterminate index test or reference standard results were handled & $8(12)$ \\
\hline & 16. How missing data were handled & $0(0)$ \\
\hline & 17. Any analyses for distinguishing pre-specified from exploratory & $5(8)$ \\
\hline & 18. Intended sample size and how it was determined & $3(5)$ \\
\hline \multirow[t]{8}{*}{ Results } & 19. Flow of participants, using a diagram & $3(5)$ \\
\hline & 20. Demographics of the participants & $20(30)$ \\
\hline & 21a. Distribution of severity of disease in those with the target condition & $19(29)$ \\
\hline & 21b. Distribution of alternative diagnoses in those without the target condition & $7(11)$ \\
\hline & 22. Time interval between index test and reference standard & $6(9)$ \\
\hline & 23. Cross tabulation of the index test results & $34(52)$ \\
\hline & 24. Estimates of diagnostic accuracy and precision & $53(80)$ \\
\hline & 25. Any adverse events & $0(0)$ \\
\hline
\end{tabular}


Table 2. Continued

\begin{tabular}{|c|c|c|}
\hline Report section & Item number and description & Number (\%) of studies, $\mathrm{N}=66$ \\
\hline \multirow[t]{3}{*}{ Discussion } & 26. Study limitations & $40(61)$ \\
\hline & 27a. Intended use of the index test & $65(98)$ \\
\hline & 27b. Clinical role of the index test & $15(23)$ \\
\hline \multirow[t]{3}{*}{ Other information } & 28. Registration number and name of registry & $3(5)$ \\
\hline & 29. Where the full study protocol can be accessed & $3(5)$ \\
\hline & 30. Sources of funding and other support; role of funders & $43(65)$ \\
\hline
\end{tabular}

Revised schema from STARD 2015 statement [2-4]. The STARD 2015 is released under the Creative Commons CC BY-NC license (http://creativecommons. org/licenses/by-nc/4.0).

handling of indeterminate (item 15) or missing (item 16) data was reported in $12 \%$ and $0 \%$ of the studies, respectively. Analyses of variability in diagnostic accuracy were reported in only $8 \%$ of studies, and only $5 \%$ of the studies reported the intended sample size and how it was determined. Indeterminate or missing data are common in all types of biomedical researches [17, 23, 24]. Missing data can occur in index or reference standard testing and pose a challenge when evaluating the performance of a diagnostic test [17]. The source of funding, including the role of the funder (item 30), was reported in 65\% of the studies. Frequently, authors did report the source of funding, but did not describe the role of the funder. Registration number and name of registry (item 28) as well as full study protocol details (item 29) were reported in only $5 \%$ of the studies.

Diagnostic accuracy studies are sensitive to a number of unique sources of bias $[5,25]$. Bias can occur at several stages, including the study population, test protocol, reference standard and verification process, and interpretation and analysis [22, 25, 26]. We identified several common biases in the diagnostic accuracy reports in ALM. First, spectrum bias (related to STARD items 6-9), which arises from differences in demographic features or disease severity, and bias in patient selection occurred frequently $[22,25,26]$. In a study evaluating the performance of a hepatitis $\mathrm{C}$ virus $(\mathrm{HCV})$ rapid antibody test, the authors recruited 137 patients diagnosed as having HCV infection and 300 healthy blood donors, and reported a sensitivity of $97.8 \%$ and specificity of $100 \%$ [27]. We would expect the diagnostic accuracy to be greater in this study because it was conducted in patients with confirmed rather than suspected disease, as the former are encountered more often in practice. Therefore, data obtained from studies in populations with significant differences in disease severity may not be comparable [5].

Second, partial verification bias (data for only a selected sample of patients who underwent the index test are verified by the reference standard, related to STARD items 16 and 19) was also common [22, 25]. For example, in one study, monoplex PCR was used as a reference test for some selected samples (17\%, 74/426 samples) that showed discrepancies between two index multiplex PCR tests to detect 16 respiratory viruses [28], indicating partial verification bias. Such a bias might increase the probability of falsely elevated sensitivity and falsely decreased specificity [5]. Third, incorporation bias (the result of the index test is included as a criterion for the reference standard, related to STARD item 11) can be observed at the interpretation stage $[5,25]$. For example, in a study on molecular detection of human papillomavirus (HPV), the authors calculated the sensitivity and specificity of each index test based on consensus HPV results between the three index tests [29]. One study reported higher sensitivity and lower specificity in the presence of incorporation bias [30]. In the era of evidence-based medicine, researchers should recognize the importance of biases and try to avoid their common sources. Furthermore, researchers should mention potential sources of bias in the discussion section (related to STARD item 26) to inform the reader of the limitations of their study and to accurately present the results and conclusions of the study [17].

The current study has several limitations: (1) we evaluated only 66 diagnostic accuracy studies, (2) since the articles evaluated were published in a single journal, findings cannot be generalized to reports in other journals, (3) no further analysis was performed on specific features such as study purpose, test areas, markers, instruments, or target conditions, and (4) several STARD 2015 items are open to interpretation and are rather subjective. We tried to minimize this limitation by defining each item in detail, performing pilot exercises, and conducting thorough discussions during consensus meetings. On the other hand, this study has the following strengths: (1) this is the first study to estimate the adherence of laboratory diagnostic accuracy studies published in ALM to STARD 2015 and (2) we analyzed STARD 2015 items in as much detail as possible. For ex- 
ample, STARD for abstract (item 2) encompass a list of 11 essential sub-items [14]. Except for the last sub-item on study registration, the remaining 10 sub-items were analyzed individually, allowing detailed evaluation of which sub-items were aptly adhered to (Table 2).

Taken together, our results show that adherence of diagnostic accuracy studies published in ALM to STARD 2015 is low, and more work and effort are needed to improve the reporting quality of such studies. Our data emphasize the necessity of adopting STARD to enhance the value of future diagnostic accuracy studies to be published in ALM.

\section{AUTHOR CONTRIBUTIONS}

Conceptualization: Mi-Ae Jang, Bohyun Kim, and You Kyoung Lee. Data curation \& formal analysis: Mi-Ae Jang and Bohyun Kim. Project administration \& supervision: You Kyoung Lee. Validation: Mi-Ae Jang, Bohyun Kim, and You Kyoung Lee. Writingoriginal draft preparation: Mi-Ae Jang and Bohyun Kim. Writingreview \& editing: Mi-Ae Jang, Bohyun Kim, You Kyoung Lee. All authors read and approved the final manuscript.

\section{CONFLICTS OF INTEREST}

No potential conflicts of interest relevant to this article are reported.

\section{RESEARCH FUNDING}

This work was supported by the Soonchunhyang University Research Fund.

\section{ORCID}

$\begin{array}{ll}\text { Mi-Ae Jang } & \text { https://orcid.org/0000-0002-6558-5236 } \\ \text { Bohyun Kim } & \text { https://orcid.org/0000-0003-4456-5612 } \\ \text { You Kyoung Lee } & \text { https://orcid.org/0000-0003-1835-2007 }\end{array}$

\section{REFERENCES}

1. Kosack CS, Page AL, Klatser PR. A guide to aid the selection of diagnostic tests. Bull World Health Organ 2017;95:639-45.

2. Bossuyt PM, Reitsma JB, Bruns DE, Gatsonis CA, Glasziou PP, Irwig L, et al. STARD 2015: an updated list of essential items for reporting diagnostic accuracy studies. BMJ 2015;351:h5527.

3. Bossuyt PM, Reitsma JB, Bruns DE, Gatsonis CA, Glasziou PP, Irwig L, et al. STARD 2015: An Updated List of Essential Items for Reporting Diagnostic Accuracy Studies. Clin Chem 2015;61:1446-52.
4. Bossuyt PM, Reitsma JB, Bruns DE, Gatsonis CA, Glasziou PP, Irwig L, et al. STARD 2015: An Updated List of Essential Items for Reporting Diagnostic Accuracy Studies. Radiology 2015;277:826-32.

5. Schmidt RL and Factor RE. Understanding sources of bias in diagnostic accuracy studies. Arch Pathol Lab Med 2013;137:558-65.

6. Reid MC, Lachs MS, Feinstein AR. Use of methodological standards in diagnostic test research. Getting better but still not good. JAMA 1995; 274:645-51.

7. Glasziou P, Altman DG, Bossuyt P, Boutron I, Clarke M, Julious S, et al. Reducing waste from incomplete or unusable reports of biomedical research. Lancet 2014;383:267-76.

8. Bossuyt PM, Reitsma JB, Bruns DE, Gatsonis CA, Glasziou PP, Irwig LM, et al. The STARD statement for reporting studies of diagnostic accuracy: explanation and elaboration. Clin Chem 2003;49:7-18.

9. Bossuyt PM, Reitsma JB, Bruns DE, Gatsonis CA, Glasziou PP, Irwig LM, et al. Towards complete and accurate reporting of studies of diagnostic accuracy: the STARD initiative. The Standards for Reporting of Diagnostic Accuracy Group. Croat Med J 2003;44:635-8.

10. Korevaar DA, Wang J, van Enst WA, Leeflang MM, Hooft L, Smidt N, et al. Reporting diagnostic accuracy studies: some improvements after 10 years of STARD. Radiology 2015;274:781-9.

11. Korevaar DA, van Enst WA, Spijker R, Bossuyt PM, Hooft L. Reporting quality of diagnostic accuracy studies: a systematic review and metaanalysis of investigations on adherence to STARD. Evid Based Med 2014; 19:47-54.

12. Smidt N, Rutjes AW, van der Windt DA, Ostelo RW, Bossuyt PM, Reitsma JB, et al. The quality of diagnostic accuracy studies since the STARD statement: has it improved? Neurology 2006;67:792-7.

13. Kim JH. Editorial announcement regarding title change of the Korean Journal of Laboratory Medicine to Annals of Laboratory Medicine. Ann Lab Med 2012;32:1-2.

14. Cohen JF, Korevaar DA, Gatsonis CA, Glasziou PP, Hooft L, Moher D, et al. STARD for Abstracts: essential items for reporting diagnostic accuracy studies in journal or conference abstracts. BMJ 2017;358:3751.

15. Walther S, Schueler S, Tackmann R, Schuetz GM, Schlattmann P, Dewey M. Compliance with STARD checklist among studies of coronary CT angiography: systematic review. Radiology 2014;271:74-86.

16. Choi YJ, Chung MS, Koo HJ, Park JE, Yoon HM, Park SH. Does the reporting quality of diagnostic test accuracy studies, as defined by STARD 2015, affect citation? Korean J Radiol 2016;17:706-14.

17. Cohen JF, Korevaar DA, Altman DG, Bruns DE, Gatsonis CA, Hooft L, et al. STARD 2015 guidelines for reporting diagnostic accuracy studies: explanation and elaboration. BMJ Open 2016;6:e012799.

18. Landis JR and Koch GG. The measurement of observer agreement for categorical data. Biometrics 1977;33:159-74.

19. Michelessi M, Lucenteforte E, Miele A, Oddone F, Crescioli G, Fameli V, et al. Diagnostic accuracy research in glaucoma is still incompletely reported: an application of Standards for Reporting of Diagnostic Accuracy Studies (STARD) 2015. PLoS One 2017;12:e0189716.

20. Hong PJ, Korevaar DA, McGrath TA, Ziai H, Frank R, Alabousi M, et al. Reporting of imaging diagnostic accuracy studies with focus on MRI subgroup: adherence to STARD 2015. J Magn Reson Imaging 2018;47: 523-44.

21. Fontela PS, Pant Pai N, Schiller I, Dendukuri N, Ramsay A, Pai M. Quality and reporting of diagnostic accuracy studies in TB, HIV and malaria: evaluation using QUADAS and STARD standards. PLoS One 2009;4: e7753.

22. Whiting PF, Rutjes AW, Westwood ME, Mallett S, QUADAS-2 Steering Group. A systematic review classifies sources of bias and variation in diagnostic test accuracy studies. J Clin Epidemiol 2013;66:1093-104. 
23. Shinkins B, Thompson M, Mallett S, Perera R. Diagnostic accuracy studies: how to report and analyse inconclusive test results. BMJ 2013;346: f2778.

24. Naaktgeboren CA, de Groot JA, Rutjes AW, Bossuyt PM, Reitsma JB, Moons KG. Anticipating missing reference standard data when planning diagnostic accuracy studies. BMJ 2016;352:1402.

25. Whiting PF, Rutjes AW, Westwood ME, Mallett S, Deeks JJ, Reitsma JB, et al. QUADAS-2: a revised tool for the quality assessment of diagnostic accuracy studies. Ann Intern Med 2011;155:529-36.

26. Sterne JA, Hernán MA, Reeves BC, Savović J, Berkman ND, Viswanathan M, et al. ROBINS-I: a tool for assessing risk of bias in non-randomised studies of interventions. BMJ 2016;355:14919.

27. Cha YJ, Park Q, Kang ES, Yoo BC, Park KU, Kim JW, et al. Performance evaluation of the OraQuick hepatitis $C$ virus rapid antibody test. Ann Lab
Med 2013;33:184-9.

28. Lee J, Lee HS, Cho YG, Choi SI, Kim DS. Evaluation of Allplex Respiratory Panel 1/2/3 multiplex real-time PCR assays for the detection of respiratory viruses with influenza A virus subtyping. Ann Lab Med 2018; 38:46-50.

29. Hwang $Y$ and Lee M. Comparison of the AdvanSure human papillomavirus screening real-time PCR, the Abbott RealTime high risk human papillomavirus test, and the Hybrid Capture human papillomavirus DNA test for the detection of human papillomavirus. Ann Lab Med 2012;32: 201-5.

30. Gupta A and Roehrborn CG. Verification and incorporation biases in studies assessing screening tests: prostate-specific antigen as an example. Urology 2004;64:106-11. 
Supplemental Data Table S1. Complete list of studies included in the current study and their overall STARD adherence

\begin{tabular}{|c|c|c|c|c|c|c|}
\hline Year & Volume & Page & Type & $\begin{array}{l}\text { Specific } \\
\text { area }\end{array}$ & Study title & $\begin{array}{l}\text { STARD } \\
\text { items }\end{array}$ \\
\hline 012 & 32 & $23-30$ & $\mathrm{OA}$ & CC & $\begin{array}{l}\text { Diagnostic utility of osteocalcin, undercarboxylated osteocalcin, and alkaline phosphatase for osteoporosis in } \\
\text { premenopausal and postmenopausal women. }\end{array}$ & 12.0 \\
\hline 2012 & 32 & $79-81$ & $\mathrm{BC}$ & $\mathrm{CM}$ & Evaluation of a new immunochromatographic assay kit for the rapid detection of norovirus in fecal specimens. & 10.4 \\
\hline 2012 & 32 & $133-138$ & $O A$ & $\mathrm{CM}$ & $\begin{array}{l}\text { Comparison of sputum and nasopharyngeal swab specimens for molecular diagnosis of Mycoplasma } \\
\text { pneumoniae, Chlamydophila pneumoniae, and Legionella pneumophila. }\end{array}$ & 9.3 \\
\hline 2012 & 32 & 201-205 & $O A$ & $\mathrm{CM}$ & $\begin{array}{l}\text { Comparison of the AdvanSure human papillomavirus screening real-time PCR, the Abbott RealTime High Risk } \\
\text { human papillomavirus test, and the Hybrid Capture human papillomavirus DNA test for the detection of } \\
\text { human papillomavirus. }\end{array}$ & 8.1 \\
\hline 2012 & 32 & $257-263$ & $\mathrm{OA}$ & $\mathrm{CM}$ & $\begin{array}{l}\text { Evaluation of peptide nucleic acid probe-based real-time PCR for detection of Mycobacterium tuberculosis } \\
\text { complex and nontuberculous mycobacteria in respiratory specimens. }\end{array}$ & 8.4 \\
\hline 2012 & 32 & $331-338$ & $\mathrm{OA}$ & DI & $\begin{array}{l}\text { Clinical usefulness of cell-based indirect immunofluorescence assay for the detection of aquaporin-4 } \\
\text { antibodies in neuromyelitis optica spectrum disorder. }\end{array}$ & 14.3 \\
\hline 2012 & 32 & $355-358$ & $\mathrm{BC}$ & $\mathrm{CM}$ & Evaluation of the Xpert Clostridium difficile assay for the diagnosis of Clostridium difficile infection. & 9.0 \\
\hline 2012 & 32 & $407-412$ & $O A$ & $\mathrm{CM}$ & $\begin{array}{l}\text { Methicillin-resistant Staphylococcus aureus in nasal surveillance swabs at an intensive care unit: an } \\
\text { evaluation of the LightCycler MRSA advanced test. }\end{array}$ & 10.1 \\
\hline 2013 & 33 & $34-38$ & $\mathrm{OA}$ & CC & Point of care D-dimer testing in the emergency department: a bioequivalence study. & 13.3 \\
\hline 2013 & 33 & 39-44 & $O A$ & $\mathrm{CM}$ & Usefulness of a rapid real-time PCR assay in prenatal screening for group B streptococ & 9.8 \\
\hline 2013 & 33 & $45-51$ & $O A$ & $\mathrm{DI}$ & Association between elevated pleural interleukin-33 levels and tuberculous pleurisy. & 12.8 \\
\hline 2013 & 33 & $105-110$ & $\mathrm{OA}$ & $\mathrm{DH}$ & $\begin{array}{l}\text { Role of the neutrophil-lymphocyte count ratio in the differential diagnosis between pulmonary tuberculosis and } \\
\text { bacterial community-acquired pneumonia. }\end{array}$ & 14.0 \\
\hline 2013 & 33 & $174-183$ & $\mathrm{OA}$ & $\mathrm{DI}$ & Flow cytometric human leukocyte antigen-B27 typing with stored samples for batch testing. & 8.5 \\
\hline 2013 & 33 & 184-189 & $\mathrm{OA}$ & $\mathrm{DI}$ & Performance evaluation of the OraQuick hepatitis C virus rapid antibody test. & 8.6 \\
\hline 2013 & 33 & $255-260$ & $O A$ & $\mathrm{CM}$ & $\begin{array}{l}\text { Comparative evaluation of three chromogenic media combined with broth enrichment and the rec } \\
\text { based Xpert MRSA assay for screening of methicillin-resistant Staphylococcus aureus in nasal }\end{array}$ & 11.3 \\
\hline 2013 & 33 & $326-330$ & $O A$ & $\mathrm{CM}$ & $\begin{array}{l}\text { Evaluation of vancomycin resistance } 3 \text { multiplexed PCR assay for detection of vancomycin-resistant } \\
\text { enterococci from rectal swabs. }\end{array}$ & 8.6 \\
\hline 2013 & 33 & $420-425$ & $O A$ & $\mathrm{DI}$ & $\begin{array}{l}\text { Reduction of the HIV seroconversion window period and false positive rate by using ADVIA Centaur HIV antigen/ } \\
\text { antibody combo assay. }\end{array}$ & 11.5 \\
\hline 2013 & 33 & 449-454 & $O A$ & GLM & $\begin{array}{l}\text { Procalcitonin and C-reactive protein in the diagnosis and prediction of spontaneous bacterial peritonitis } \\
\text { associated with chronic severe hepatitis B. }\end{array}$ & 14.5 \\
\hline 2014 & 34 & $51-55$ & $\mathrm{BC}$ & $\mathrm{CM}$ & $\begin{array}{l}\text { Assessment of the quantitative ability of AdvanSure TB/NTM real-time PCR in respiratory specimens by } \\
\text { comparison with phenotypic methods. }\end{array}$ & 7.6 \\
\hline 2014 & 34 & $85-91$ & $O A$ & DH & $\begin{array}{l}\text { Changes in plasma levels of natural anticoagulants in disseminated intravascular coagulation: high } \\
\text { prognostic value of antithrombin and protein } \mathrm{C} \text { in patients with underlying sepsis or severe infection. }\end{array}$ & 11.0 \\
\hline 2014 & 34 & 127-133 & $O A$ & $D G$ & $\begin{array}{l}\text { Clinical validation of AdvanSure GenoBlot assay as primary screening and test of cure for human } \\
\text { papillomavirus infection. }\end{array}$ & 7.1 \\
\hline 2014 & 34 & 203-209 & $O A$ & $\mathrm{CM}$ & $\begin{array}{l}\text { Evaluation of propidium monoazide real-time PCR for early detection of viable Mycobacterium tuberculosis in } \\
\text { clinical respiratory specimens. }\end{array}$ & 12.1 \\
\hline 2014 & 34 & $235-239$ & $B C$ & $\mathrm{CM}$ & $\begin{array}{l}\text { Evaluation of a rapid membrane enzyme immunoassay for the simultaneous detection of glutamate } \\
\text { dehydrogenase and toxin for the diagnosis of Clostridium difficile infection. }\end{array}$ & 10.2 \\
\hline 2014 & 34 & $354-359$ & $O A$ & $\mathrm{CM}$ & $\begin{array}{l}\text { Evaluation of the optimal neutrophil gelatinase-associated lipocalin value as a screening biomarker for urinary } \\
\text { tract infections in children. }\end{array}$ & 8.5 \\
\hline 2014 & 34 & $376-379$ & $\mathrm{BC}$ & $\mathrm{CM}$ & $\begin{array}{l}\text { Performance of chromID Clostridium difficile agar compared with BBL C. difficile selective agar for detection of } \\
\text { C. difficile in stool specimens. }\end{array}$ & 13.1 \\
\hline 2015 & 35 & $28-34$ & $O A$ & $\mathrm{DH}$ & Flow cytometric white blood cell differential using CytoDiff is excellent for counting blasts. & 8.6 \\
\hline
\end{tabular}


Supplemental Data Table S1. Continued

\begin{tabular}{|c|c|c|c|c|c|c|}
\hline Year & Volume & Page & Type & $\begin{array}{l}\text { Specific } \\
\text { area }\end{array}$ & Study title & $\begin{array}{l}\text { STARD } \\
\text { items }\end{array}$ \\
\hline 2015 & 35 & $35-40$ & $O A$ & $\mathrm{DH}$ & $\begin{array}{l}\text { A novel marker for screening paroxysmal nocturnal hemoglobinuria using routine complete blood count and cell } \\
\text { population data. }\end{array}$ & 9 \\
\hline 2015 & 35 & $50-56$ & $O A$ & CM & $\begin{array}{l}\text { Highly sensitive and novel point-of-care system, aQcare Chlamydia TRF kit for detecting Chlamydia } \\
\text { trachomatis by using europium (Eu) (III) chelated nanoparticles. }\end{array}$ & 10.6 \\
\hline 2015 & 35 & $62-68$ & $O A$ & $\mathrm{CM}$ & $\begin{array}{l}\text { Evaluation of matrix-assisted laser desorption ionization-time of flight mass spectrometry-based VITEK MS } \\
\text { system for the identification of Acinetobacter species from blood cultures: comparison with VITEK } 2 \text { and } \\
\text { MicroScan systems. }\end{array}$ & 7.7 \\
\hline 2015 & 35 & $76-81$ & $O A$ & $\mathrm{CM}$ & $\begin{array}{l}\text { Evaluation of the iNtRON VRE vanA/vanB real-time PCR assay for detection of vancomycin-resistant } \\
\text { enterococci. }\end{array}$ & 14.2 \\
\hline 2015 & 35 & $212-219$ & $O A$ & $\mathrm{CM}$ & $\begin{array}{l}\text { Combined use of the modified Hodge test and carbapenemase inhibition test for detection of carbapenemase- } \\
\text { producing Enterobacteriaceae and metallo- } \beta \text {-lactamase-producing Pseudomonas spp. }\end{array}$ & 7.4 \\
\hline 2015 & 35 & 298-305 & $O A$ & $\mathrm{CM}$ & $\begin{array}{l}\text { Further modification of the modified Hodge test for detecting metallo- } \beta \text {-Lactamase-producing carbapenem- } \\
\text { resistant Enterobacteriaceae. }\end{array}$ & 11.5 \\
\hline 2015 & 35 & $306-313$ & $O A$ & $\mathrm{CM}$ & $\begin{array}{l}\text { Multiplex teal-time PCR method for simultaneous identification and toxigenic type characterization of } \\
\text { Clostridium difficile from stool samples. }\end{array}$ & 13.7 \\
\hline 2015 & 35 & $356-361$ & $\mathrm{BC}$ & $\mathrm{CM}$ & $\begin{array}{l}\text { Comparison of AdvanSure TB/NTM PCR and COBAS TaqMan MTB PCR for detection of Mycobacterium } \\
\text { tuberculosis complex in routine clinical practice. }\end{array}$ & 9.2 \\
\hline 2015 & 35 & $454-457$ & $\mathrm{BC}$ & $\mathrm{CM}$ & $\begin{array}{l}\text { Direct identification of Staphylococcus aureus and determination of methicillin susceptibility from positive } \\
\text { blood-culture bottles in a Bact/ALERT system using Binax Now S. aureus and PBP2a tests. }\end{array}$ & 13.1 \\
\hline 2015 & 35 & $487-493$ & $O A$ & $\mathrm{CM}$ & $\begin{array}{l}\text { Detection of first-line anti-tuberculosis drug resistance mutations by allele-specific primer extension on a } \\
\text { microsphere-based platform. }\end{array}$ & 7.6 \\
\hline 2015 & 35 & $500-505$ & $O A$ & $\mathrm{CM}$ & $\begin{array}{l}\text { Evaluation of dual-color fluorescence in situ hybridization with peptide nucleic acid probes for the detection of } \\
\text { Mycobacterium tuberculosis and non-tuberculous mycobacteria in clinical specimens. }\end{array}$ & 9.6 \\
\hline 2016 & 36 & $1-8$ & $O A$ & $\mathrm{DH}$ & $\begin{array}{l}\text { Immature platelet fraction in septic patients: clinical relevance of immature platelet fraction is limited to the } \\
\text { sensitive and accurate discrimination of septic patients from non-septic patients, not to the discrimination } \\
\text { of sepsis severity. }\end{array}$ & 13.5 \\
\hline 2016 & 36 & $131-137$ & $O A$ & $\mathrm{CM}$ & $\begin{array}{l}\text { Evaluation of Xpert C. difficile, BD MAX Cdiff, IMDx C. difficile for Abbott m2000, and Illumigene C. difficile } \\
\text { assays for direct detection of toxigenic Clostridium difficile in stool specimens. }\end{array}$ & 9.9 \\
\hline 2016 & 36 & 291-299 & $O A$ & $\mathrm{DH}$ & Screening PCR versus Sanger sequencing: detection of CALR mutations in patients with thrombocytosis. & 13.4 \\
\hline 2016 & 36 & $405-412$ & $\mathrm{OA}$ & $\mathrm{CC}$ & Can a point-of-care troponin I assay be as good as a central laboratory assay? A MIDAS investigation & 16.8 \\
\hline 2016 & 36 & $434-440$ & $O A$ & $\mathrm{CM}$ & $\begin{array}{l}\text { Disk carbapenemase test for the rapid detection of KPC-, NDM-, and other metallo- } \beta \text {-lactamase-producing } \\
\text { gram-negative bacilli }\end{array}$ & 6.8 \\
\hline 2016 & 36 & $441-449$ & $O A$ & $\mathrm{CM}$ & $\begin{array}{l}\text { Analysis of the vaginal microbiome by next-generation sequencing and evaluation of its performance as a } \\
\text { clinical diagnostic tool in vaginitis }\end{array}$ & 8.5 \\
\hline 2016 & 36 & $542-549$ & $\mathrm{OA}$ & $\mathrm{DI}$ & Soluble ST2 levels and left ventricular structure and function in patients with metabolic syndrome & 12.0 \\
\hline 2017 & 37 & 28-33 & $\mathrm{OA}$ & CC & $\begin{array}{l}\text { Comparison of urine albumin-to-creatinine ratio (ACR) between ACR strip test and quantitative test in } \\
\text { prediabetes and diabetes }\end{array}$ & 14.7 \\
\hline 2017 & 37 & $39-44$ & $\mathrm{OA}$ & $\mathrm{CM}$ & $\begin{array}{l}\text { Evaluation of BD MAX Staph SR assay for differentiating between Staphylococcus aureus and coagulase- } \\
\text { negative Staphylococci and determining methicillin resistance directly from positive blood cultures }\end{array}$ & 10.1 \\
\hline 2017 & 37 & $53-57$ & $\mathrm{BC}$ & $\mathrm{CM}$ & Fecal calprotectin level reflects the severity of Clostridium difficile infection & 12.0 \\
\hline 2017 & 37 & 240-247 & $\mathrm{OA}$ & DI & Performance of an automated fluorescence antinuclear antibody image analyzer & 11.9 \\
\hline 2017 & 37 & $267-271$ & $\mathrm{BC}$ & $\mathrm{CM}$ & $\begin{array}{l}\text { Comparison of luminex NxTAG respiratory pathogen panel and xTAG respiratory viral panel FAST version } 2 \text { for } \\
\text { the detection of respiratory viruses }\end{array}$ & 7 \\
\hline 2017 & 37 & $305-312$ & $O A$ & CM & $\begin{array}{l}\text { Evaluation of six phenotypic methods for the detection of carbapenemases in gram-negative bacteria with } \\
\text { characterized resistance mechanisms }\end{array}$ & 9.1 \\
\hline
\end{tabular}


Supplemental Data Table S1. Continued

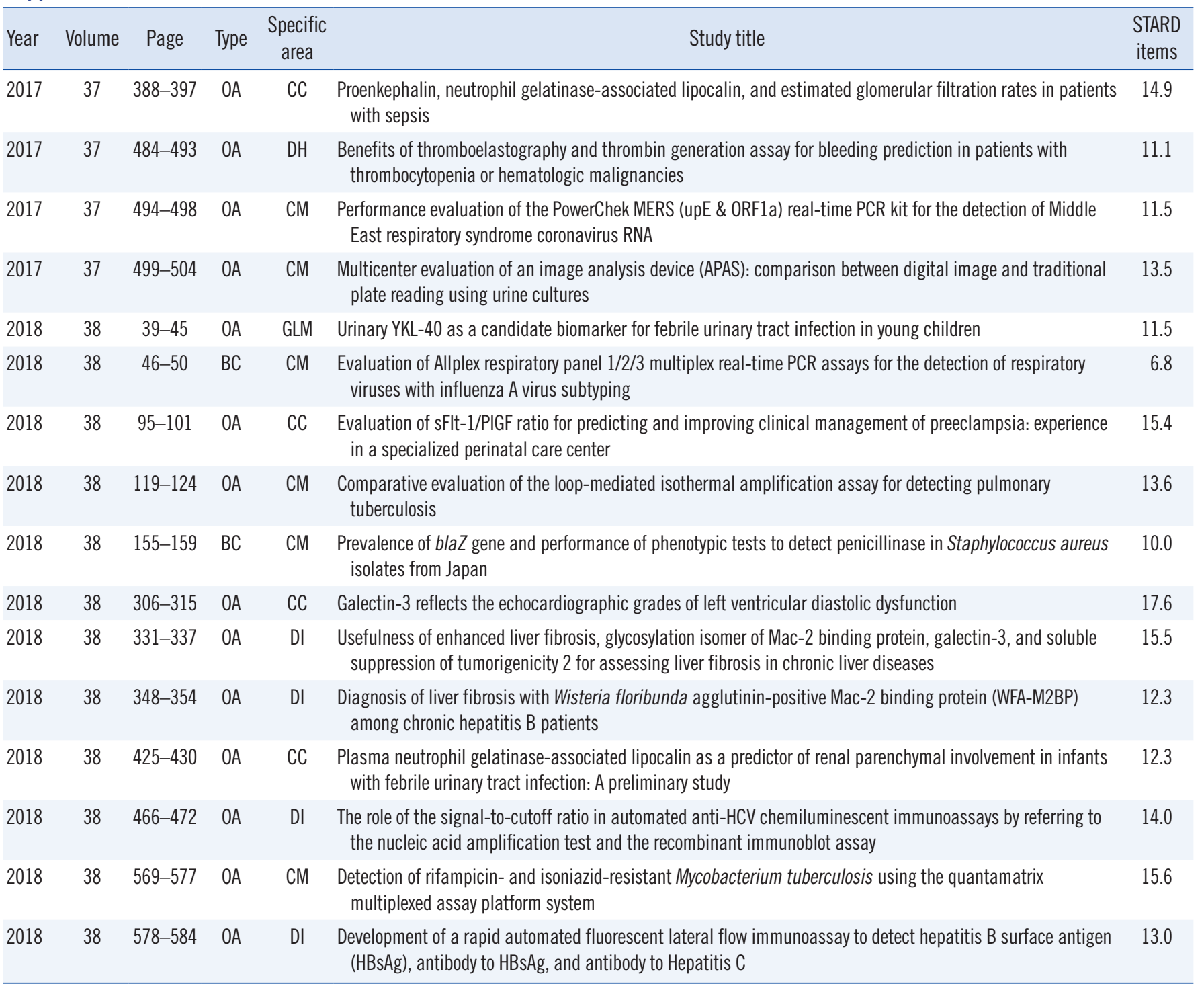

Abbreviations: BC, Brief Communication; CC, Clinical Chemistry; CM, Clinical Microbiology; DG, Diagnostic Genetics; DH, Diagnostic Hematology; DI, Diagnostic Immunology; GLM, General Laboratory Medicine; HCV, hepatitis C virus; MERS, Middle East respiratory syndrome coronavirus; MRSA, methicillin-resistant Staphylococcus aureus; MTB, Mycobacterium tuberculosis; OA, Original Article; sFIt-1/PIGF, soluble fms-like tyrosine kinase 1/placental growth factor; STARD, Standards for Reporting of Diagnostic Accuracy; TB/NTM, tuberculosis/non-tuberculous mycobacterium; TRF, time-resolved fluorescence; VRE, vancomycin-resistant enterococci. 


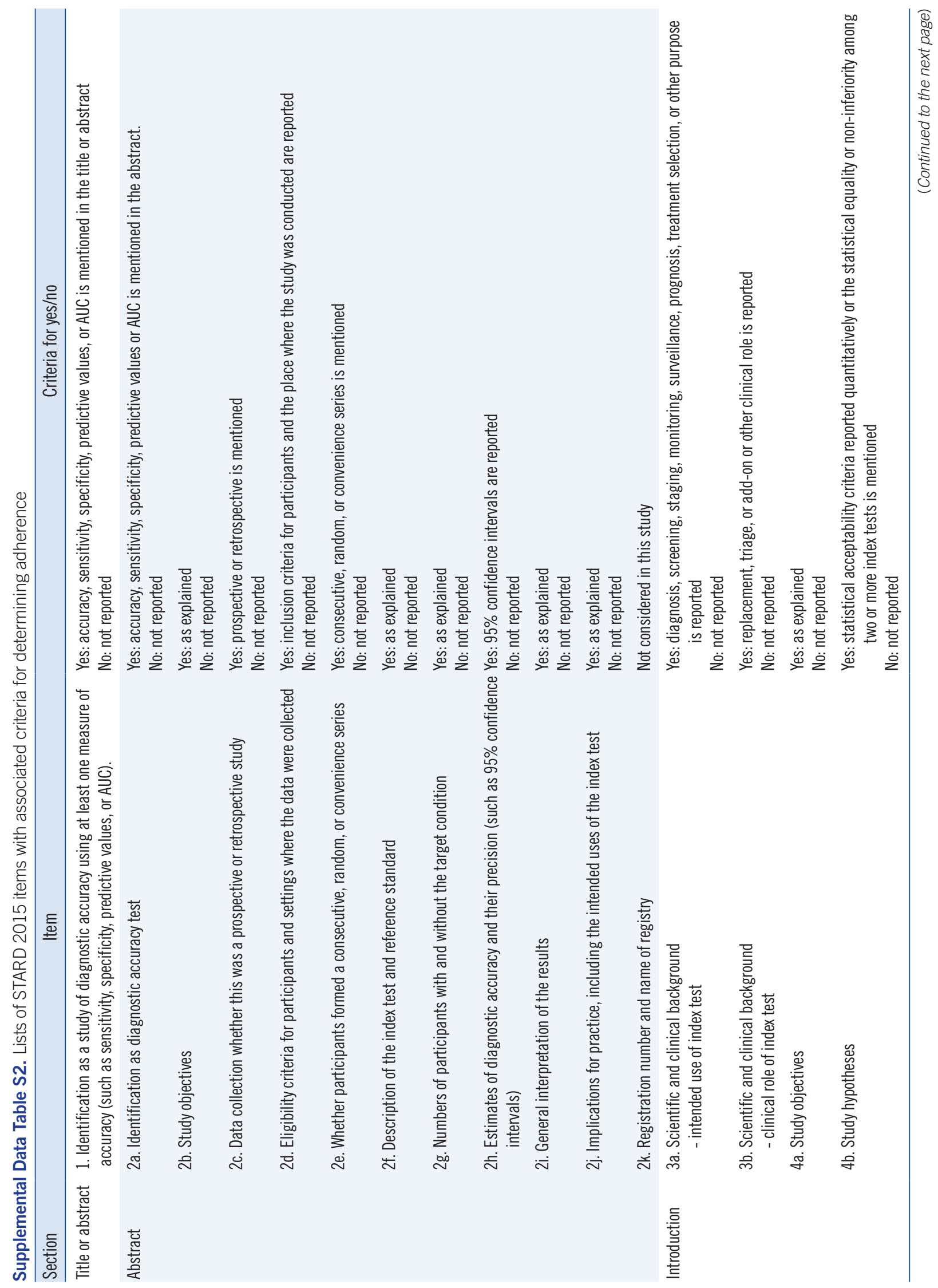




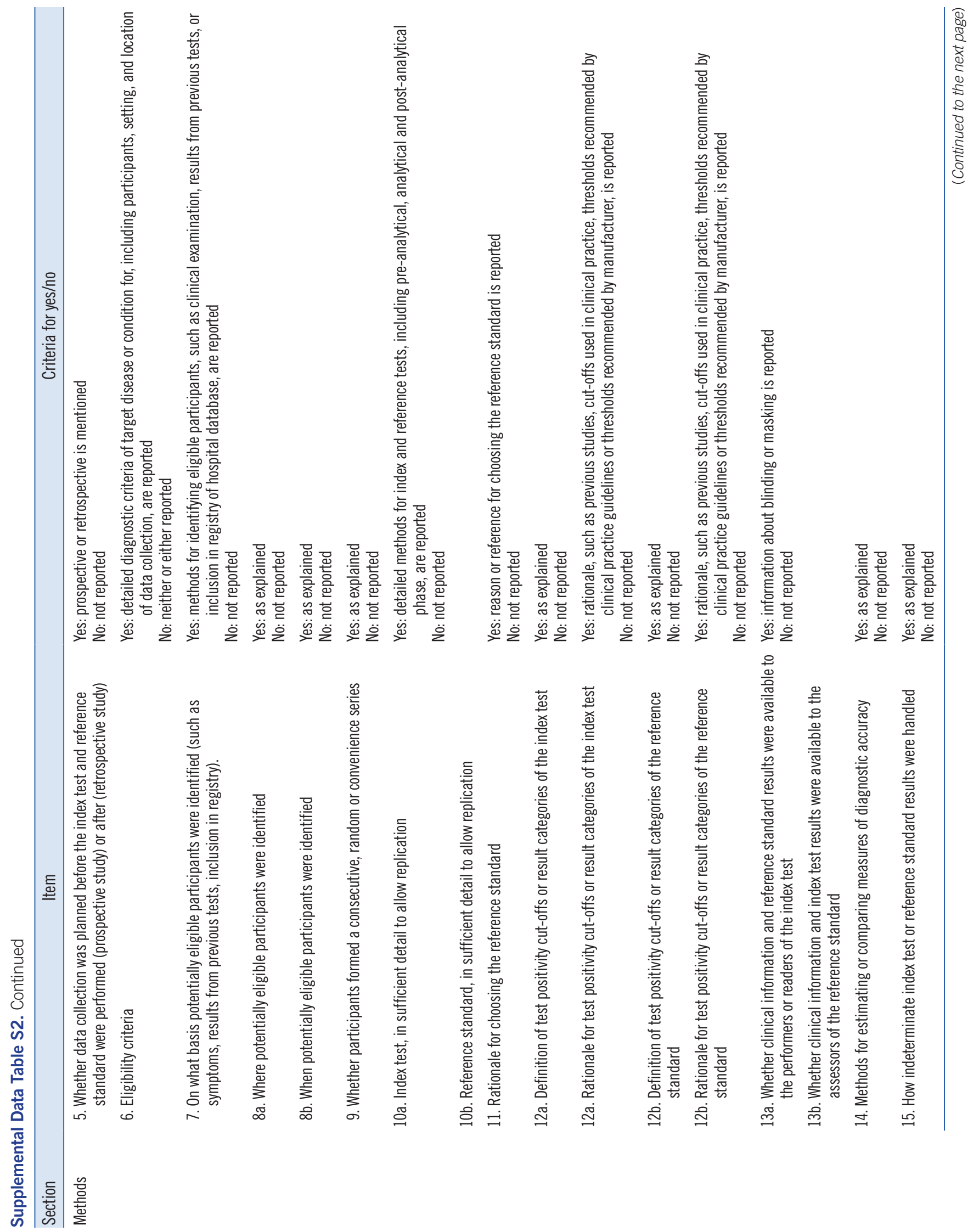




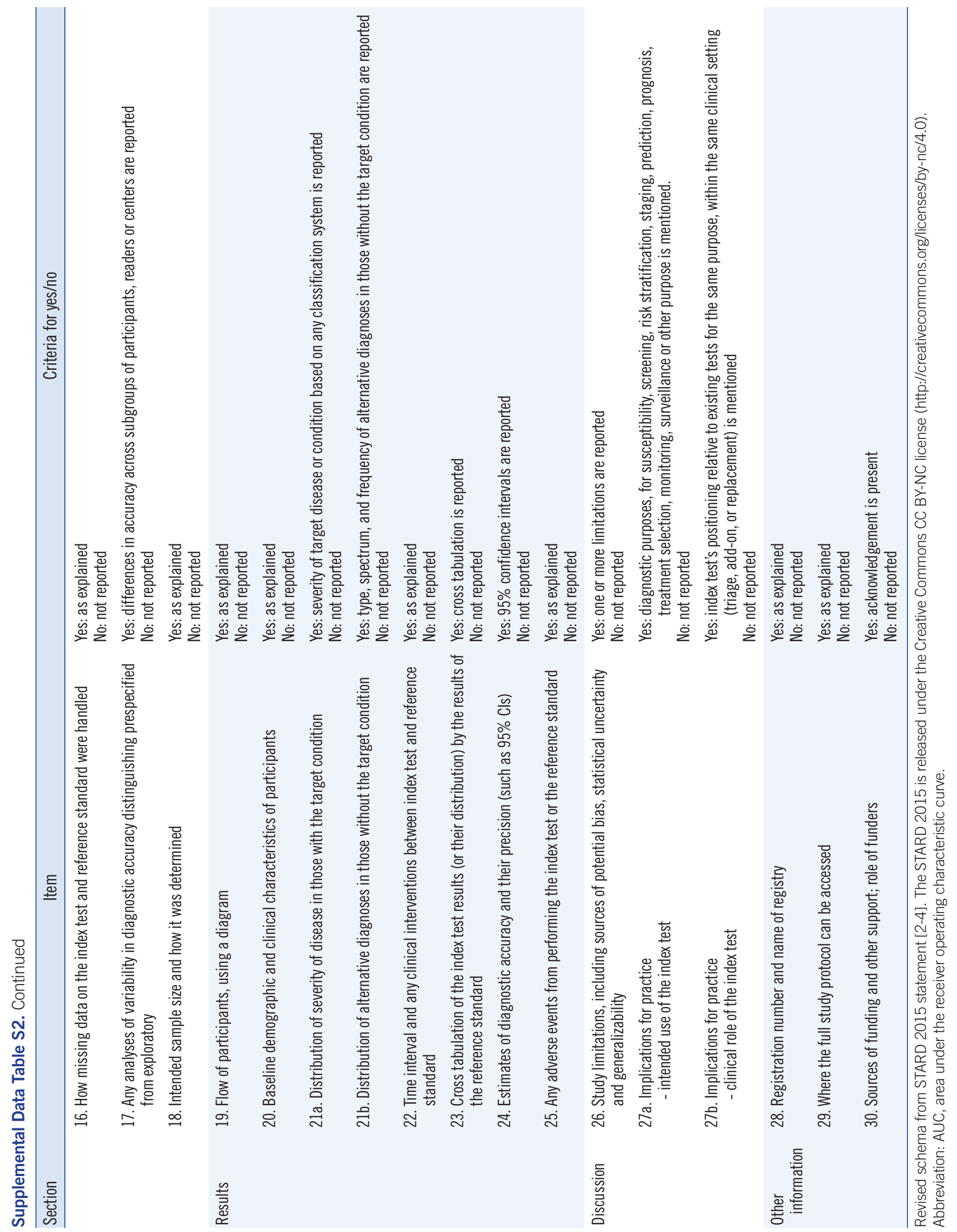

